\title{
On The Selection of Optimum Performance Bounds for CO- OFDM Systems Through Standard Fibers
}

\author{
Akriti Gupta $^{1}$ and Jyoteesh Malhotra ${ }^{2}$ \\ ${ }^{1}$ Departement of Electronics and Communication, GNDU RC, Jalandhar \\ ${ }^{2}$ Department of Electronics and Communication, GNDU RC, Jalandhar
}

\begin{abstract}
Orthogonal frequency division multiplexing (OFDM) can accomplish high use effectiveness. Various system impairments affect the performance of system. So mechanisms should be adopted to improve the performance of the system. In this paper, a 40 Gbps optical OFDM system is designed. Comparative analysis of the designed system is done using different fiber standards and dispersion compensating mechanisms on the basis of transmission distance and SNR. From the present research, it is clear that pre dispersion compensating mechanisms perform better than post ones. The fiber standards considered in present research are SMF, ALCATEL, ITU G.652, ITU G.654, and ITU G.655. Of all the fibers, ALCATEL $(\mathrm{D}=8 \mathrm{ps} / \mathrm{nm} / \mathrm{km})$ is able to cover maximum distance i.e. $660 \mathrm{~km}$ with SNR $30.08 \mathrm{~dB}$. For rest of fibers, the performance was remarkable for few hundreds of kilometres and then degraded. ITU G.655 (D=3.78 $\mathrm{ps} / \mathrm{nm} / \mathrm{km})$ gives the best SNR i.e. $32.08 \mathrm{~dB}$ upto $418 \mathrm{~km}$ then degrades due to less DCF fiber length to compensate for dispersion.
\end{abstract}

Keywords: CO-OFDM, ALCATEL, ITU G.652, ITU G.654, ITU G.655

\section{Introduction}

Optical OFDM (O-OFDM) transmission has set up to be a solid bearer for rapid information correspondence over the dispersive optical channel and it offers remarkable error free transmission for high information rate. So it could amplify the limit of optical fiber transmission frameworks [1]. While many details of OFDM systems are very complex, the essential idea of OFDM is very straightforward. Information is transmitted in parallel on various distinctive frequencies and therefore its symbol period is any longer than any other serial transmission with the same data rate [2]. Because the symbol period is longer, the equalization is simplified as the ISI affects one symbol period. In most OFDM implementations, the ISI is eliminated by utilizing a type of gatekeeper interim called a cyclic prefix [3].

OFDM is based on Multi carrier transmission which changes a wide-band channel into a gathering of narrowband channels [4]. It has developed to lead correspondence standard in almost each significant standard (Wi-Max, IEEE 802.11a, DVB). OFDM offers two principal points of interest. One is its strength against channel scattering and second is simplicity of phase and channel estimation in a period changing environment. [5].

It is known that with the increase in data rate, the transmission distance decreases due to the increase in dispersion of fiber [6]. Network operators have to keep in mind when installing new transmission lines that which fibers will best meet future traffic requirements and which dispersion compensating mechanism should be followed to achieve maximum transmission distance [7]. For high data rate transmission over the SMF, the dispersion limits the transmission distance. Hence it is of great requirement to investigate different fiber standards and different dispersion compensating mechanisms to have the maximum transmission distance and better performance of the communication system in terms of BER and SNR. 
This paper deals with the comparative analysis of $40 \mathrm{Gbps}$ CO-OFDM system with different fiber standards such as ALCATEL, ITU G.652, ITU G.654, ITU G.655, SMF along with the different dispersion compensating mechanisms such as pre and post compensation. This paper is organized as follows. After the introduction section, section II describes the simulative setup and environment used for present research work. After that, section III deals with Simulative results and discussions in form of constellation visualiser along with the performance parameter SNR and the research work is finally concluded in section IV.

\section{System Description}

A 40 Gbps CO-OFDM system is designed using Optisystem version 13 is shown in Figure 1 consists of three segments i.e., transmitter area, optical fiber connection and recipient segment. The performance of CO-OFDM framework is analysed using different fiber standards and different dispersion compensation techniques.

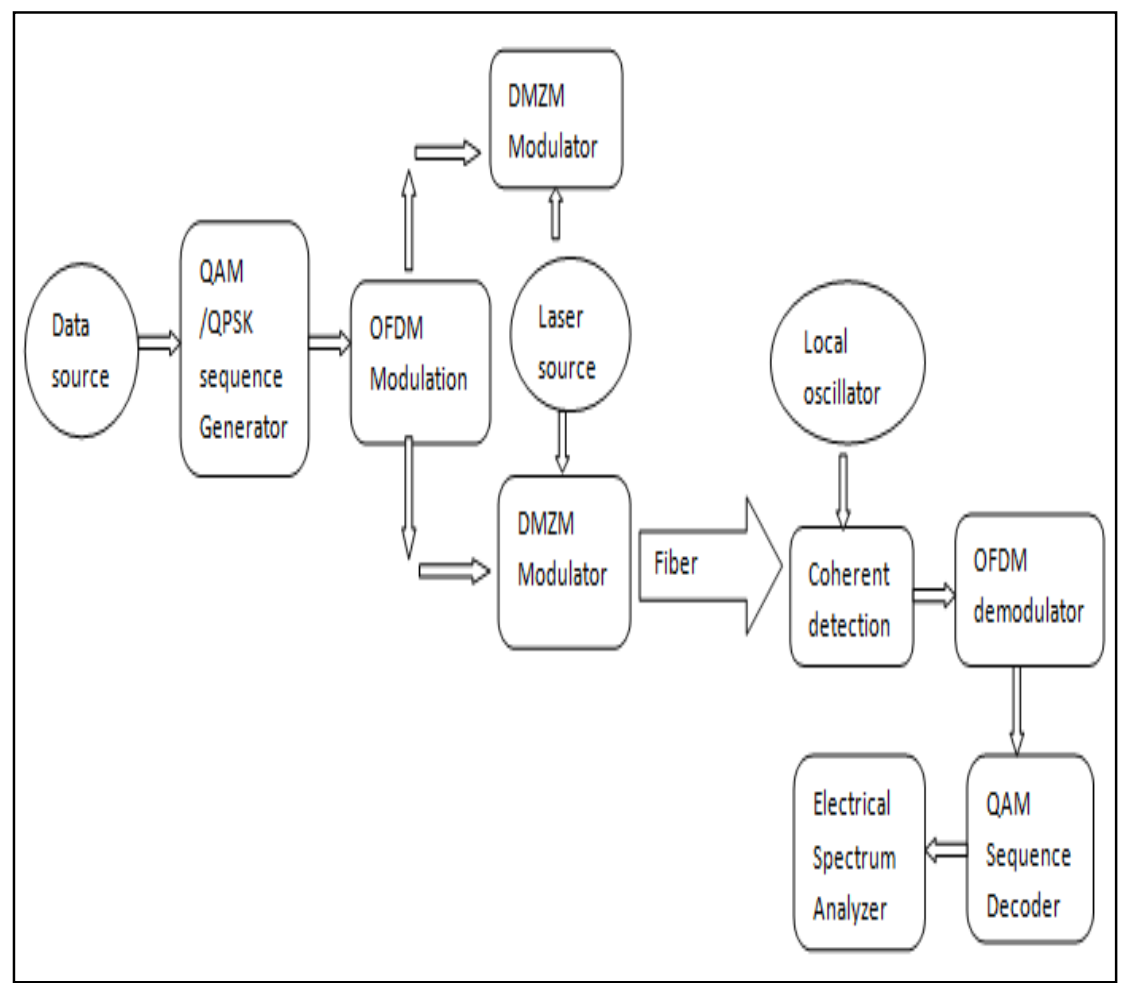

Figure 1. COOFDM System Design

\section{CO-OFDM Transmitter}

The information signal generated by QPSK sequence generator is modulated by OFDM modulator. The various parameters of OFDM modulation are described in Table 1.The modulated signal is then applied to the mach Zehnder modulator and to power combiner. The resultant signal is then dispatched to the fiber link.

Table 1. OFDM Parameters

\begin{tabular}{|l|l|}
\hline No of Subcarriers & 512 \\
\hline No of FFT points & 1024 \\
\hline No of Prefix points & 14 \\
\hline Position Array & 256 \\
\hline
\end{tabular}




\section{Optical Fiber Link}

This link consists of optical fiber, dispersion compensating scheme and loop control. The different fiber standards considered for present research are described in Table 2.

Table 2. Different Fiber Standards

\begin{tabular}{lc}
\hline Fiber Standards & $\begin{array}{l}\text { Fiber } \\
\text { Dispersion(ps/nm/km) }\end{array}$ \\
\hline SMF & 16 \\
ALCATEL & 8 \\
ITU G.652 & 17.65 \\
ITU G.654 & 20.13 \\
ITU G.655 & 3.78 \\
\hline
\end{tabular}

Different Compensating mechanisms used for the analysis are pre and post shown in Figure 2 and 3 respectively.

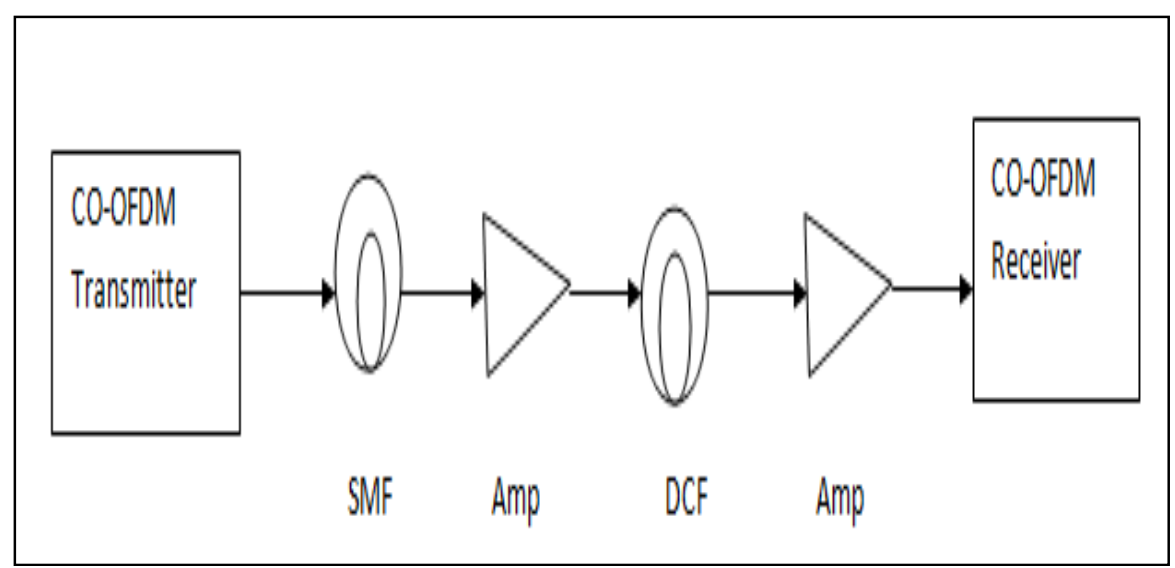

Figure 2. CO-OFDM System with Post- compensation

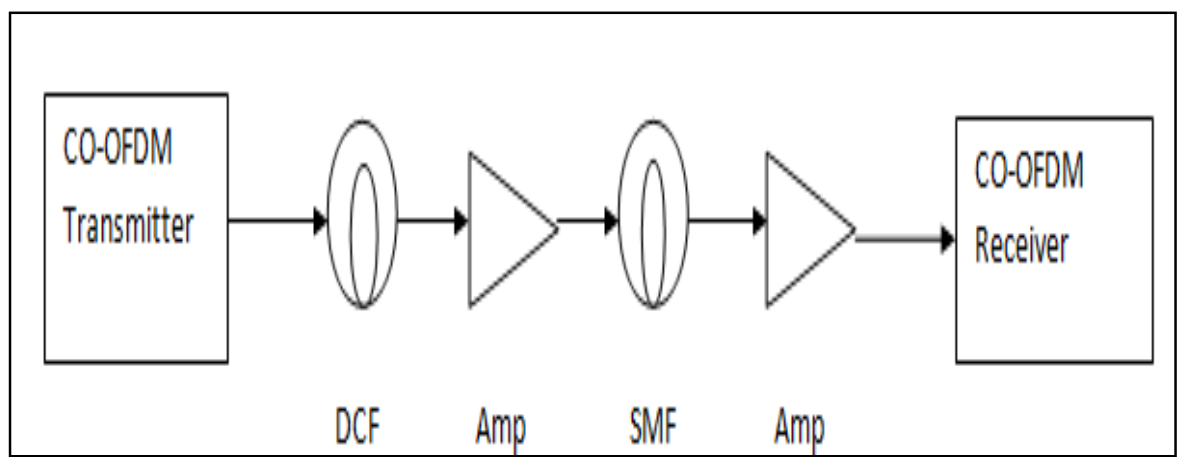

Figure 3. CO-OFDM System with Pre- compensation

\section{CO-OFDM Receiver}

The yield signal from the optical fiber is connected to the four PIN Photodectectors to covert the optical signal to electrical signal. The subsequent signal is then connected to the OFDM demodulator and after that to the QAM succession decoder to recover the information signal. The various simulation parameters are described in Table 3. 
Table 3. Simulation Parameter

\begin{tabular}{lc}
\hline \multicolumn{1}{c}{ Parameters } & Specifications \\
\hline Data Rate & $40 \mathrm{Gbps}$ \\
Power & $-4 \mathrm{~dB}$ \\
Electrical gain & -0.008 \\
Gainof amplifier & $5 \mathrm{~dB}$ \\
\hline
\end{tabular}

\section{Results and Discussions}

A 40Gbps COOFDM system is designed. Simulative investigations have been done by having all the fiber standards and dispersion compensating schemes. The optical spectrum analyser at the transmitting and receiving end is shown in Figure 4 and 5 respectively.

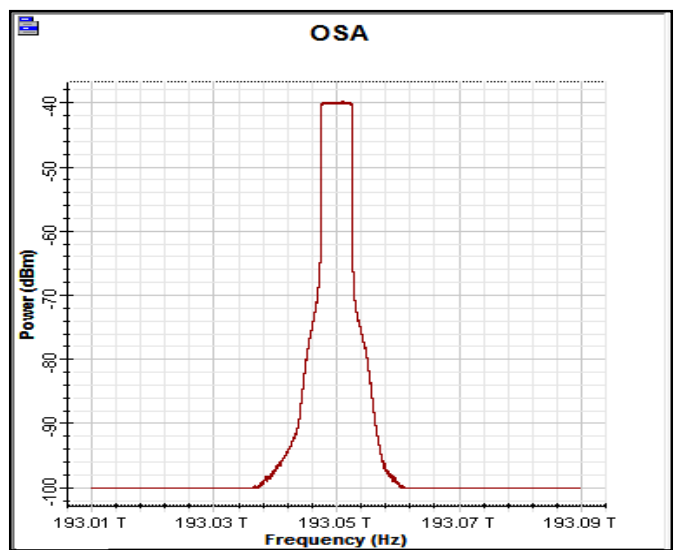

Figure 4. Spectrum at the Transmitting End

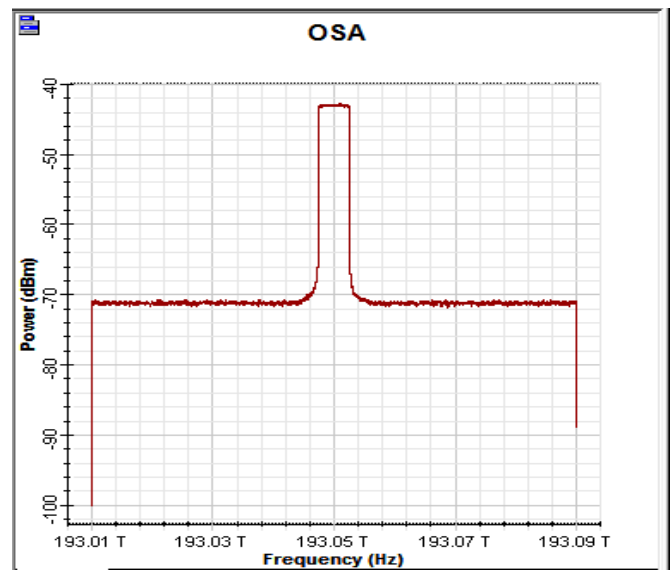

Figure 5. Spectrum at the Receiving End 


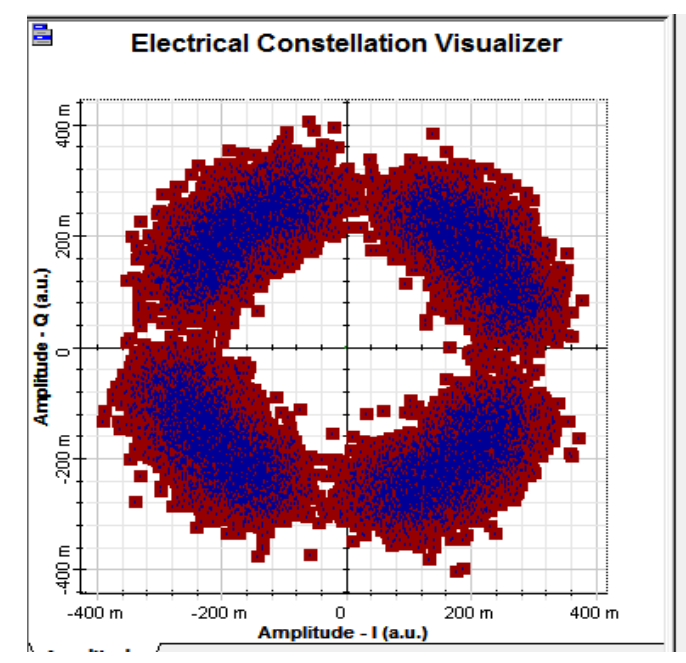

Figure 6(a). Constellation Visualizer at the Receiving End with Post Compensation for SMF

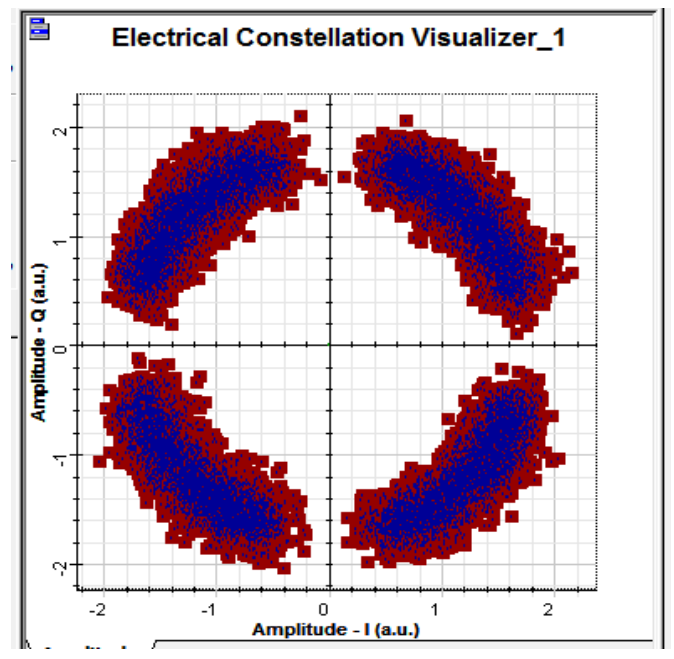

Figure 6(b). Constellation Visualizer at the Receiving End for SMF with Pre Compensation

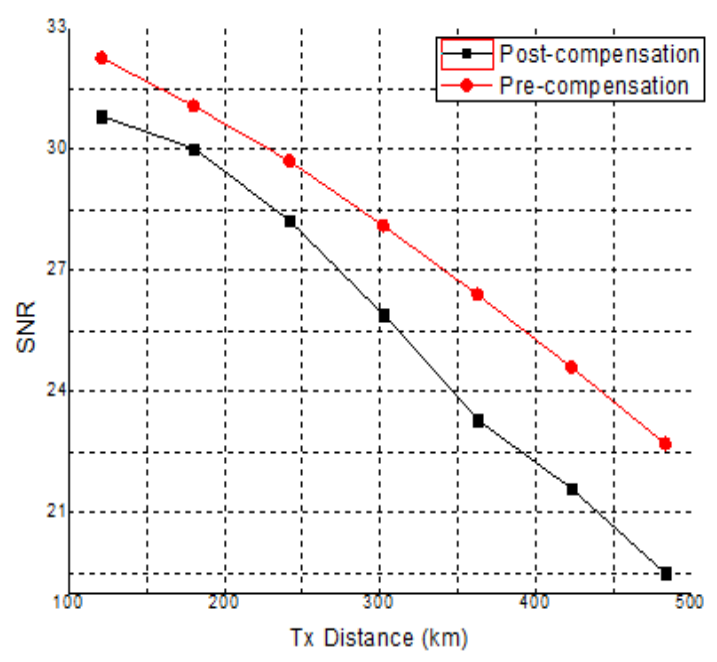

Figure 6(c). SNR v/s Transmission Distance for SMF 
The dispersion of SMF is $17.65 \mathrm{ps} / \mathrm{nm} / \mathrm{km}$. The constellation visualiser at the receiving end with pre and post dispersion compensation mechansim is shown in Figure 6(a) and 6(b). The variation of SNR with the transmission distance considering pre and post compensation is plotted in Figure 6(c). It is clear from the graph that SNR decreases almost linearly with the increase in transmission distance. At $483 \mathrm{~km}$ the SNR for post and pre dispersion compensation is $19.5 \mathrm{~dB}$ and $22.7 \mathrm{~dB}$. Therefore pre-compensation provides better SNR.

The ALCATEL fiber is having a dispersion of $8 \mathrm{ps} / \mathrm{nm} / \mathrm{km}$. The constellation visualiser at the receiving end with pre and post dispersion compensation mechansim is shown in Figure 7(a) and 7(b). The variation of SNR with the transmission distance considering pre and post compensation is plotted in Figure 7(c).

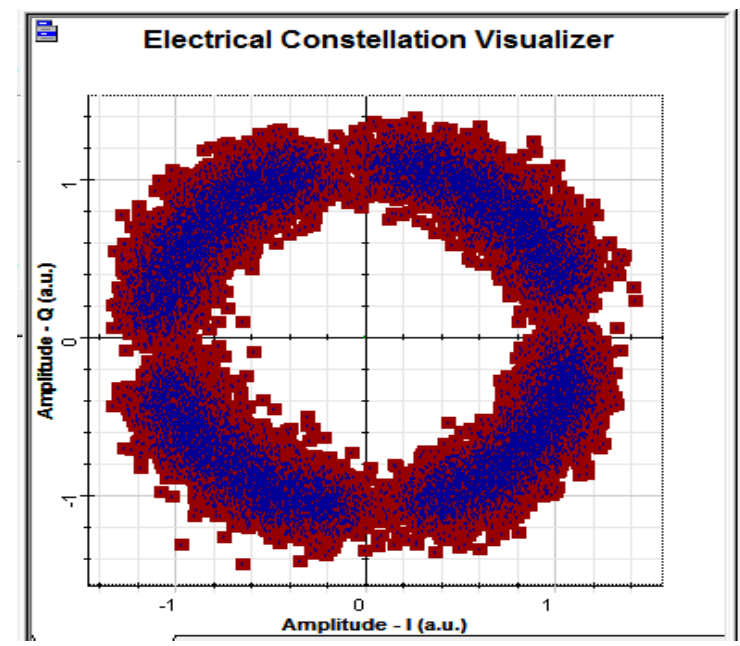

Figure 7(a). Constellation Visualizer at the Receiving End for ALCATEL with Post Compensation

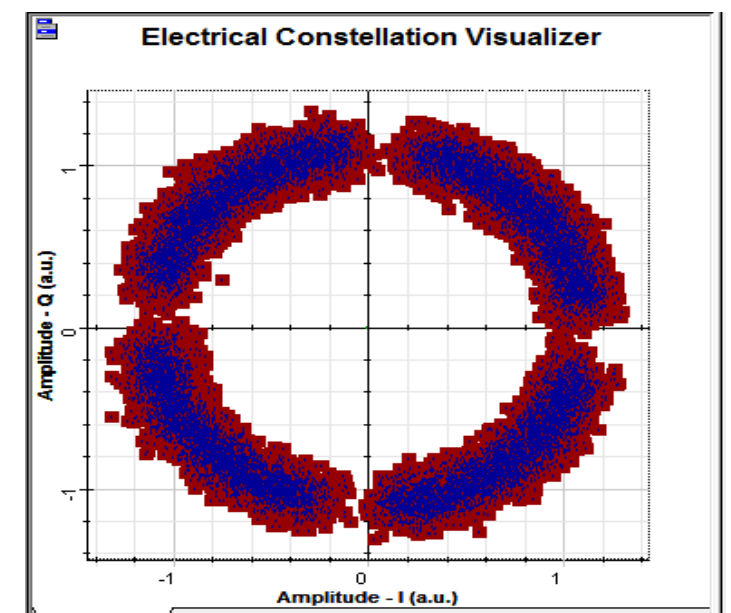

Figure 7(b). Constellation Visualizer at the Receiving End for ALCTEL with Pre Compensation 


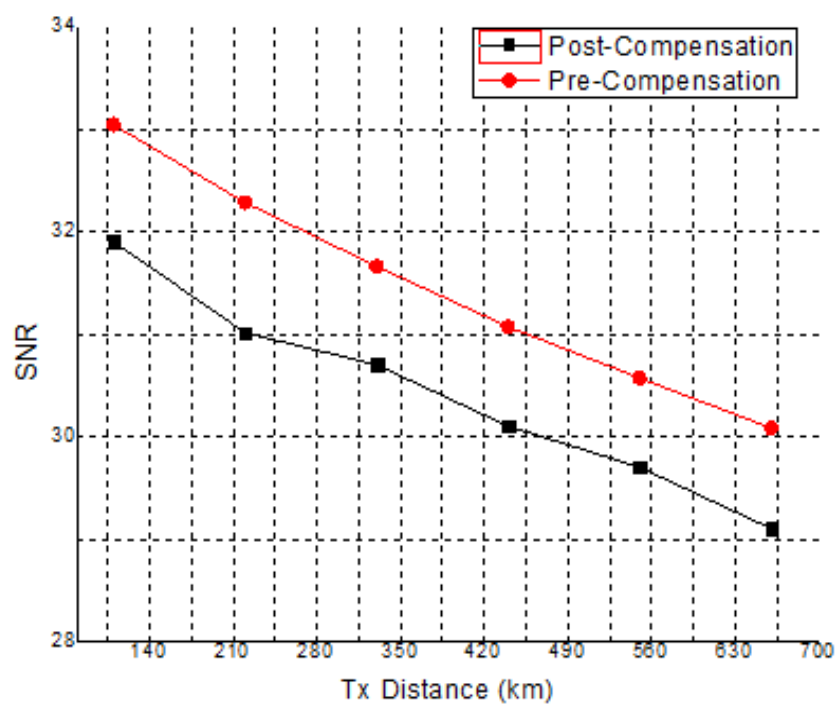

Figure 7 (c). SNR v/s Transmission Distance for ALCATEL

It is clear from the graph that SNR decreases with the increase in transmission distance. At $660 \mathrm{~km}$ the SNR for pre and post compensation mechanisms is $30.08 \mathrm{~dB}$ and 26.59 $\mathrm{dB}$. Therefore for the ALCATEL fiber, the pre compensation is better.

For this fiber, the dispersion is $17.65 \mathrm{ps} / \mathrm{nm} / \mathrm{km}$. The electrical constellation visualiser at receiving end with post and pre compensation is shown in Figure 8(a) and Figure 8(b).

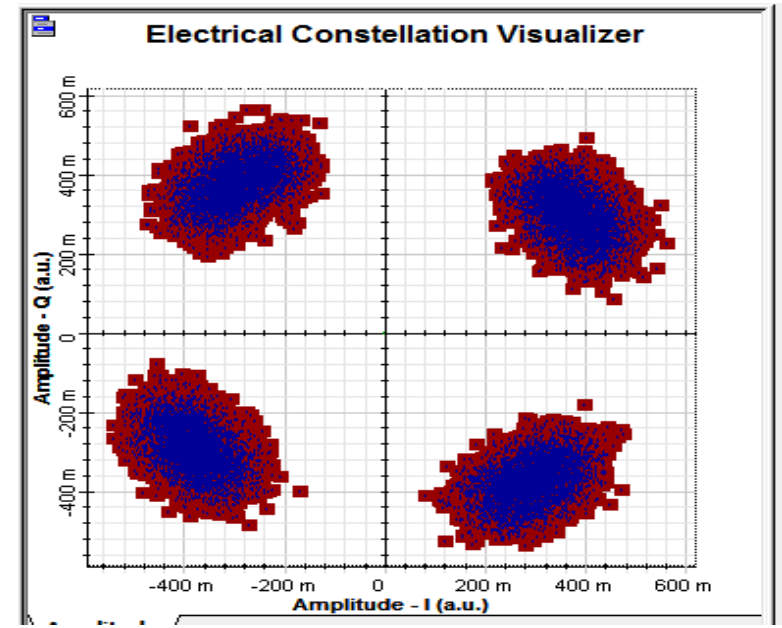

Figure 8 (a). Constellation Visualizer at the Receiving End for ITU G.652 with Post Compensation 


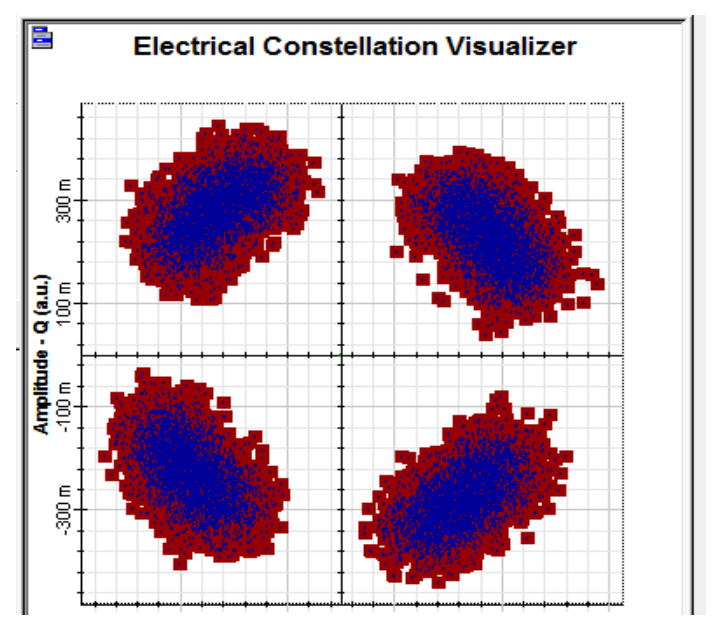

Figure 8(b). Spectrum at the Receiving End for ITU G.652 with Pre Compensation

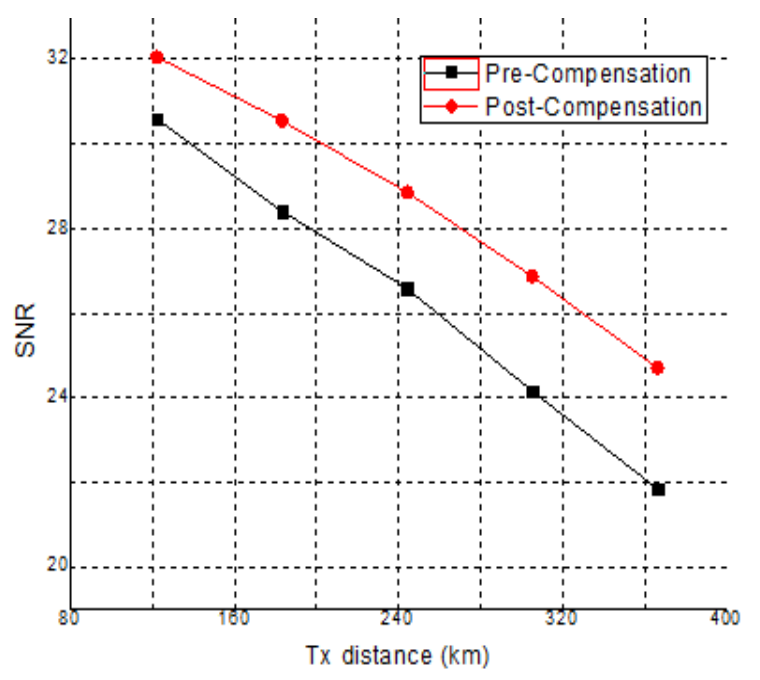

Figure 8(c). SNR v/s Transmission Distance for ITU G.652

At $366 \mathrm{~km}$, the SNR for pre and post compensation is $24.7 \mathrm{~dB}$ and $21.84 \mathrm{~dB}$. Therefore, for ITU G. 654 pre compensation is better.

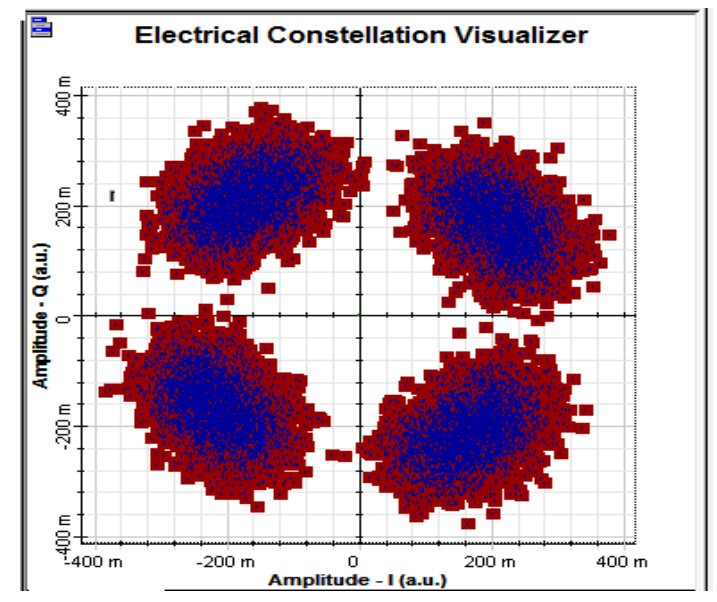

Figure 9 (a). Constellation Visualizer at the Receiving End for ITU G.654 with Post Compensation 


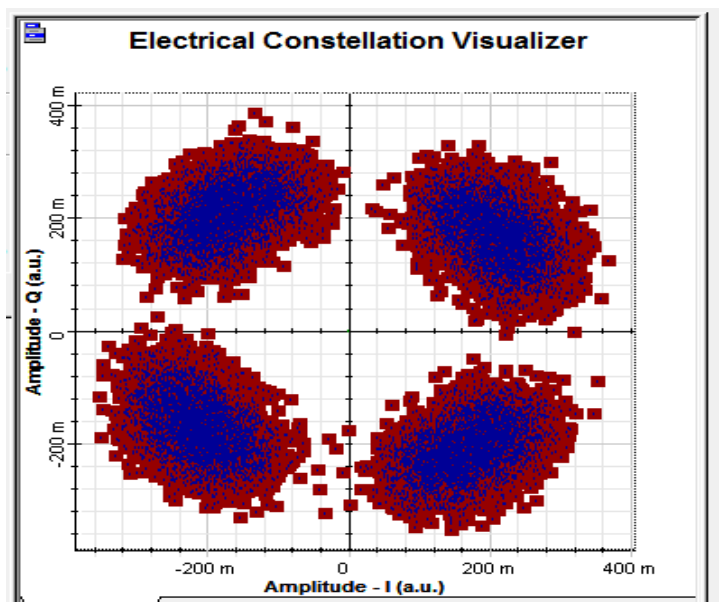

Figure 9 (b). Constellation Visualizer at the Receiving End for ITU G.654 with Post Compensation

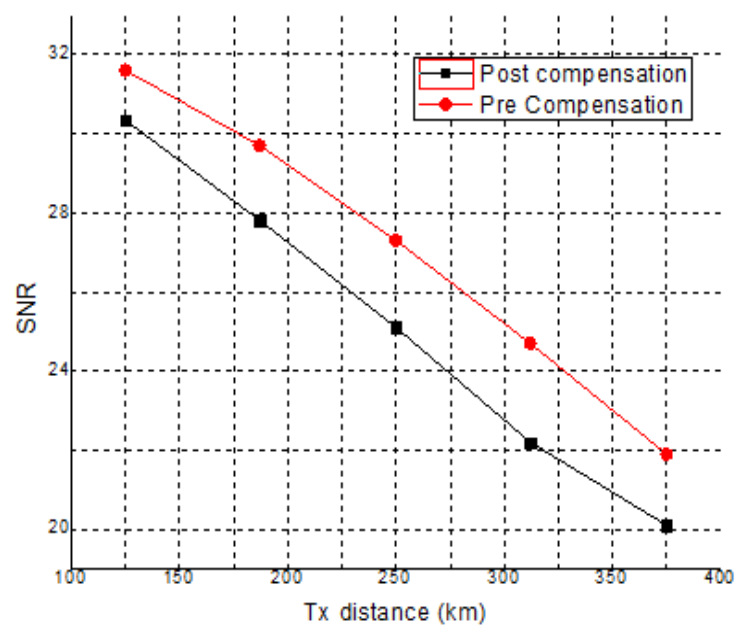

Figure 9(c). SNR v/s Transmission Distance for ITU G.654

For ITU G.654 fiber, the dispersion is $20.13 \mathrm{ps} / \mathrm{nm} / \mathrm{km}$. Constellation visualiser shown in Figure 9(a) and 9(b). It is clear from 9(c), at $375 \mathrm{~km}$ the SNR for post and pre compensation is $19.93 \mathrm{~dB}$ and $21.7 \mathrm{~dB}$.

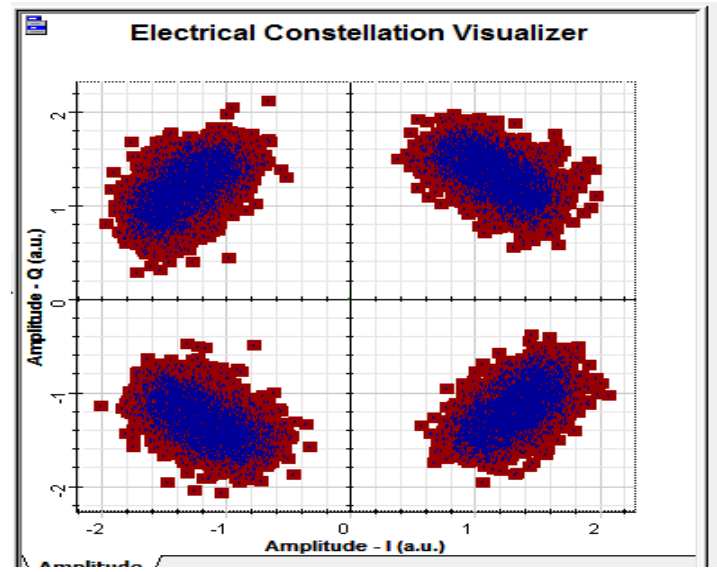

Figure 10(a). Constellation Visualizer at the Receiving End for ITU G.655 with Post Compensation 


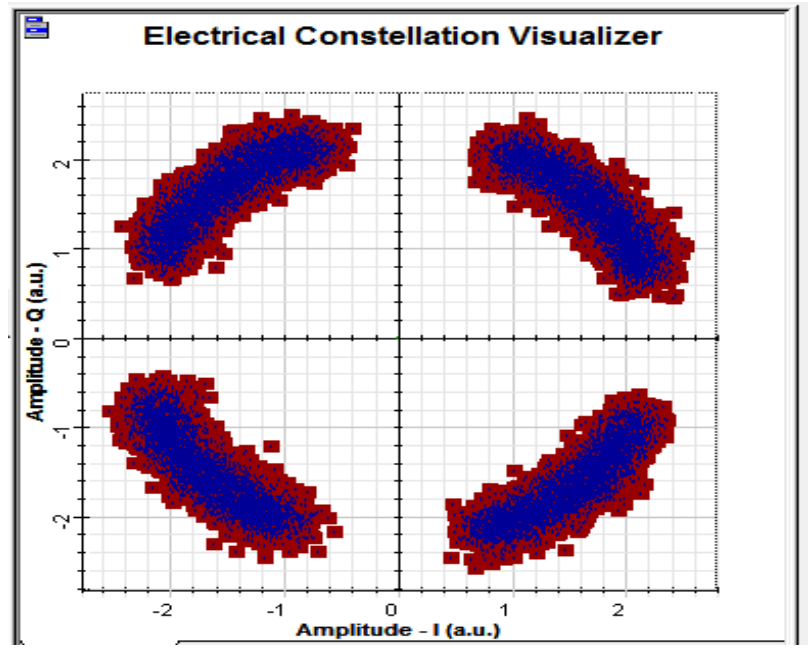

Figure 10 (b). Constellation Visualizer at the Receiving End for ITU G.655 with Post Compensation

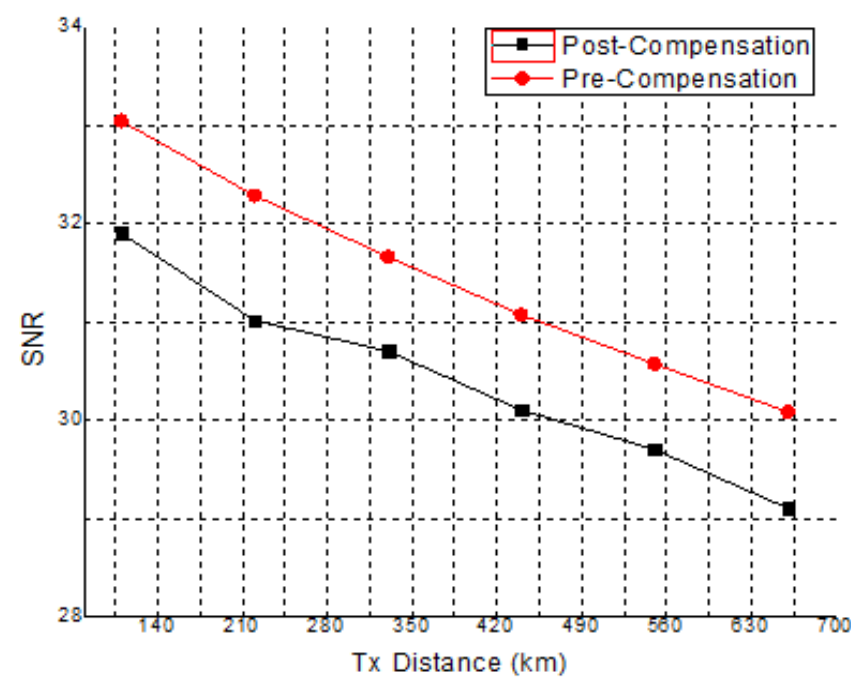

Figure 10(c). SNR v/s Transmission Distance for ITU G.655

For ITU G.655, the fiber dispersion is $3.78 \mathrm{ps} / \mathrm{nm} / \mathrm{km}$. The electrical constellation for pre compensation is better than post compensation as depicted in Figure 10 (a) and (b).

From Figure 10(c), SNR degrades with the increase in transmission distance. At 418 $\mathrm{km}$, SNR for post and pre compensation is $30.27 \mathrm{~dB}$ and $32.27 \mathrm{~dB}$ which shows is compensation is $2 \mathrm{~dB}$ better than post.

Table 4. Comparison of Different Fibres

\begin{tabular}{|l|c|c|c|}
\hline \multirow{2}{*}{$\begin{array}{c}\text { Fiber } \\
\text { Stand-ard }\end{array}$} & \multicolumn{2}{|c|}{ SNR (dB) } & $\begin{array}{c}\text { Transmission } \\
\text { Dist-ance } \\
(\mathrm{km})\end{array}$ \\
\cline { 2 - 3 } & $\begin{array}{l}\text { Post- } \\
\text { Compensation }\end{array}$ & $\begin{array}{l}\text { Pre- } \\
\text { Compensation }\end{array}$ & 483 \\
\hline SMF & 19.5 & 22.7 & 660 \\
\hline ALCATEL & 26.59 & 30.08 & 366 \\
\hline ITU G.652 & 21.84 & 26.87 & 375 \\
\hline ITU G.654 & 19.93 & 21.7 & 418 \\
\hline ITU G.655 & 30.07 & 32.26 & \\
\hline
\end{tabular}




\section{Conclusion}

A 40 Gbps CO-OFDM system is designed. Performance analysis of the system is done using different fiber standards along with different compensation techniques as shown in Table 3. It is concluded from the table that pre-compensation technique gives better performance than the post compensation technique. The ALCATEL ( $D=8 \mathrm{ps} / \mathrm{nm} / \mathrm{km}$ ) fiber has the maximum transmission distance i.e. $660 \mathrm{~km}$ than other fibers. The performance of rest of fibers is better at small distances and then degrades. ITU G.654(D= $20.13 \mathrm{ps} / \mathrm{nm} / \mathrm{km})$ covers minimum distance i.e. $366 \mathrm{~km}$. ITU G.655 (D=3.78ps $/ \mathrm{nm} / \mathrm{km})$ gives best performance in terms of SNR i.e. $32.26 \mathrm{~dB}$ but then degrades because of less DCF length to compensate dispersion.

\section{References}

[1] J. Armstrong, Senior Member, IEEE, "OFDM for Optical Communications" journal of lightwave technology, vol. 27, no. 3, (2009).

[2] K. Alatawi, F. Almasoudi, "Integration of Coherent Optical OFDM with WDM", Proceedings of SPIE, vol. 885, (2015), pp.1-10.

[3] M. Singh and K. Kaur, "Coherent Detection WDM Optical OFDM", International Journal of Advanced Research in Computer and Communication Engineering, vol. 2, iss. 12, (2013).

[4] N. Cvijetic, M. Cvijetic, M. F. Huang, E. Ip, Y. K. Huang and T. Wang, "Terabit Optical Access Networks Based on WDM-OFDMA-PON”, Journal of lightwave technology”, vol. 30, no. 4, (2012), pp. 493-503.

[5] J. A. L. Silva, A.V. T. Cartaxo and M. E. V. Segatto, "A PAPR reduction technique based on a Constant Envelope OFDM approach for fiber nonlinearity mitigation in optical direct-detection systems", J. Opt. Commun. Netw., vol. 4, no. 4, (2012).

[6] G. Zhang, M. D. Leenheer and B. Mukherjee, "Optical Traffic Grooming in OFDM-Based Elastic Optical Networks", Journal of Opt. Commun. Netw., vol. 4, no. 11, (2012), pp. B17-B25.

[7] M. S. Moreolo, J. M. Fàbrega, L. Nadal and J. Vílchez, "Software-Defined Optical OFDM Transmission Systems: Enabling Elasticity in the Data Plane", Conference paper on Transparent optical networks, vol. 23, (2012), pp. 1-4.

[8] H. Wang, D. Kong, Y. Li, J. Wu and J. Lin, "Performance evaluation of (D)APSK modulated coherent optical OFDM system", optical fiber technology, vol. 19, (2013), pp. 242-249.

[9] I. K. Mizrahi, "Low-cost adaptive directly modulated optical OFDM based on semiconductor optical amplifier", Optical Fiber Technology, vol. 19, iss. 5, (2013), pp. 501-506.

[10] S. Zhang and C. L. Bai, "An improved least square channel estimation algorithm for coherent optical OFDM system", optic, vol. 123, (2013), pp. 5937-5940.

[11] L. Liu, "Chromatic dispersion compensation using two pilot tones in optical OFDM systems", IEEE Trans., vol. 8309, (2011), pp. 1-6.

[12] K. Qiu, X. Vi, L. Zhang, H. Zhang, M. Deng and C. Zhang, "OFDM-PON Optical Fiber Access Technologies”, Proceedings of SPIE-OSA-IEEE, vol. 8309, (2011). 
International Journal of Future Generation Communication and Networking Vol. 9, No.9, (2016) 